\title{
Single Slope Shore Protection as a Wave Energy Catcher
}

\author{
Muhammad Arsyad Thaha ${ }^{1, *}$, Mukhsan $\mathrm{P} \mathrm{H}^{1}$, A. Subhan, M. ${ }^{1}$, and A. Ildha Dwipuspita ${ }^{1}$ \\ ${ }^{1}$ Civil Engineering Department, Hasanuddin University, Makassar, 90245, INDONESIA
}

\begin{abstract}
Wave energy is being increasingly regarded in many countries as a major, promising and renewable resource. This paper presents the development of slope coastal protection as a wave energy converter by capturing sea water into the reservoir through overtopping process. Physical models simulation were conducted at The Laboratory of Coastal Engineering, Hasanuddin University. A model of $30 \mathrm{~cm} \times 90 \mathrm{~cm}$ in the $30^{\circ}$ degree of slope made from acrylic material equipped with a reservoir at the top surface of the structures to catch seawater through run up and overtopping. Models were simulated with various wave high and periods as well as high of freeboard. The results showed that the overtopping discharge $(Q)$ much influenced by relative freeboard height $\left(F_{b} / d\right)$, wave steepness $\left(H_{i} / L\right)$, reflected waves $\left(K_{r}\right)$ and the number of standing waves $\left(N_{s w}\right)$. The increasing $F_{b}$, the decreasing $Q$; the increasing wave steepness, the increasing overtopping discharge. It was found that the larger the reflection coefficient, the greater the discharge overtopping. Standing waves in front of the structure due to the superposition of the incident wave and reflection waves also contribute to enlarge the overtopping discharge.
\end{abstract}

\section{Introduction}

Wave energy is a type of well-concentrated renewable energy when compared to other renewable energy resources, such as solar, wind etc., and it has a huge potentials. It is recognized that efficiently of utilizing of wave energy may make significant contributions to achieve the target of green energy and offer great prospects for the marine renewable energy sector.

A wave energy converter (WEC) is a device for extracting energy from waves into useful energy. Most WECs may have two or more energy conversion stages. Essentially, the first conversion stage is the primary wave energy conversion in which the wave-excited components of the device or the water bodies in oscillating water columns or overtopping devices convert wave energy into mechanical or potential energy. In the second conversion stage, a power take-off system, such as hydraulic pump/motor, direct electrical generator, air turbine or water turbine (depending on the principle of the wave energy converter), is often applied to convert the mechanical/potential energy into useful energy [6].

Drew et al. in [4] classified wave energy converter into two classification i.e. the type and the mode of operation. Wave energy converter based on type, consisting of three types: Attenuator device, for example Pelamis; Point absorber device, for example Power Buoy; and terminator device, for example Salter's duck. On a wave energy converter based on the operating mode consists of four types: first, Submerged pressure differential, for example: the Archimedes; second, Oscillating wave surge converter, for example, Oyster; third, Oscillating water column, for example the limpet; and the fourth is overtopping devices, for example the wave dragon as a floating structure and tapchan, SSG as fixed structure and resonance channel.

Overtopping devices are partially submerged wave energy converter equipped by reservoirs for capturing wave crests and water turbines to produce electricity. The kinetic energy of the waves is converted to potential energy when incoming waves are led up a ramp and collects in the reservoir. The water returns to the ocean from the reservoir through water turbines, thus utilizing the potential difference between the ocean and the reservoir to generate electricity [1].

Overtopping is defined as the amount of water, which exceeds the crest of coastal structures. The energy of incoming wave is dissipated by breaking, friction, infiltration or is reflected. The rest of the kinetic energy is

\footnotetext{
${ }^{*}$ Corresponding author: arsyad999@gmail.com
} 
transformed into potential energy. When the slope is not too long or the crest is not high enough this conversion is not total and the freeboard $(\mathrm{Fb})$ is exceeded. Consequently, some water pass over the crest of the structure as see in Figure 1.

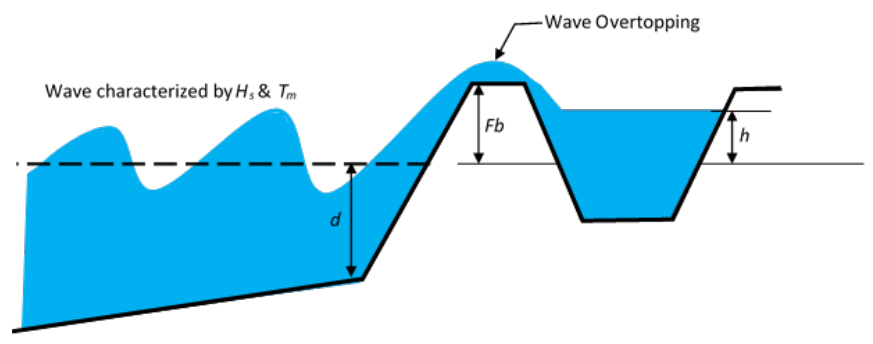

Fig. 1. Schema of overtopping process [2].

For coastal structures, the mean overtopping discharge can be calculated by empirical formulae or by physical and numerical models. Empirical formulas are based on interpolation results of tests made in physical models for structures with a specific geometry, while physical and numerical models are applications for specific situations. Due to the low cost and swiftness of empirical formulas, these are more used to estimate wave overtopping discharge. However, they are limited for a small number of geometries. These formulas are conditioned by the wave climate and the geometry of the structure. Mean overtopping discharge, $\mathrm{q}$, is a function of the parameters below [3]:

$$
q=f\left(H s, T m, \beta, F_{b}, d, g\right)
$$

$$
\begin{array}{ll}
H s & =\text { Significant wave height of the toe of the sea-wall } \\
T m & =\text { Mean wave period at the toe of the seawall } \\
\beta & =\text { Angle wave attack } \\
F_{b} & =\text { Freeboard of the seawall } \\
d & =\text { Water depth at toe of structure } \\
g & =\text { Acceleration due to gravity } \\
h & =\text { head formed }
\end{array}
$$

Some formulas consider the reduction of wave overtopping caused by slope roughness, $r$, berm, $b$, water depth, $h$, and angle wave attack, $\beta$, dividing the freeboard, $F_{b}$, for the respective reduction coefficient: $\gamma r, \gamma b . \gamma h, \gamma \beta$. In general, mean overtopping discharge is expressed by two typical forms shown in equations (2) and (3), where $a$ and $b$ are tabled coefficients that change according to the structure geometry. $Q$ and $F_{b}$ are nondimensional parameters of overtopping discharge and freeboard, respectively.

$$
\begin{gathered}
Q=a \exp \left(-b F_{b}\right) \\
Q=a R^{-b}
\end{gathered}
$$

Among the few WECs that have been built and tested is the Norwegian TAPCHAN (Tapered Channel). This device is equipped with the same machinery as a low pressure hydroelectric power station with a reservoir and a Kaplan turbine. The reservoir is fed by waves trapped by a broad channel opening that reaches into the sea. Towards the reservoir the channel is tapered and bent in such a way that the waves pile up and spill over the channel margin. Vicinanza et al. [8] development of an economically and environmentally sustainable coastal infrastructure, which combines rubble mound breakwaters with Wave Energy Converters (WEC). The energy is produced by collecting wave overtopping in a front reservoir, which is returned to the sea through turbines. 
Studies have also been performed on a variation of this coast based approach where overtopping water is not used to produce power but to recirculate water in harbors (in a project called Kingston harbor pump). This approach can be useful in locations where only a small tide exists and therefore only insufficient flushing of the harbors occurs. As the coast based overtopping devices works best in areas with small tidal ranges this can be a very useful application.

Lee and Lee, 2013 [4] develop a wave power generation device with resonance channels. The devise also works as a breakwater. The device has a sloping wall in which resonance channels are open to the sea. Behind the wall there is a reservoir which stores water passing through the channel and overtopping to the air. Under the water surface, the reservoir is connected to the rear side with a pipe in which wave power generation device exists. The sketch of the model in this research shown in figure 2 .

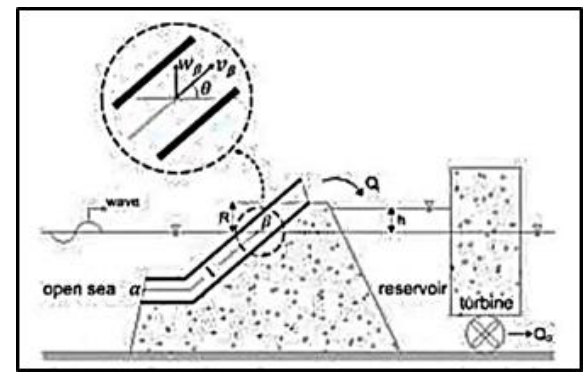

Fig. 2. Configuration of wave power generation devise with resonance channel [4].

The results of numerical experiments showed that overtopping discharge becomes maximal around the analytically predicted resonance period.

Thaha et al in previous research [7] was conducted by physical model simulations under regular wave conditions compared to the Van Der Mer result in irregular wave conditions. The results showed an over-topping discharge $(q)$ is significantly influenced by the parameters of the breakwater free-board relative to the wave height $(R c / H i)$. Both results indicated significant differences due to the different wave conditions. The graph of the relationship of overtopping discharge (q) with relative freeboard (Rc) from this research shown in Figure 3.

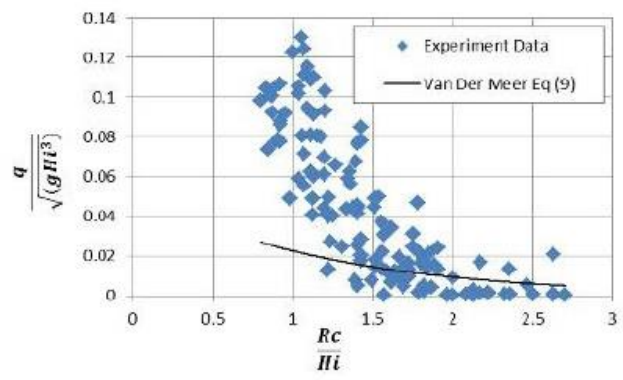

Fig. 3. Relationship over-topping discharge (q) with relative free-board (Rc) by Thaha et al compare to the Van Der Mer result [7]

Figure 3 shows that the rate of $q$ (overtopping discharge) in the regular wave condition is much larger than the Van Der Meer rate in the irregular wave conditions. Thaha et al [7] also estimated the wave power that can be captured by the model is about $34 \%$ on average. The graph shown in Figure 4. 


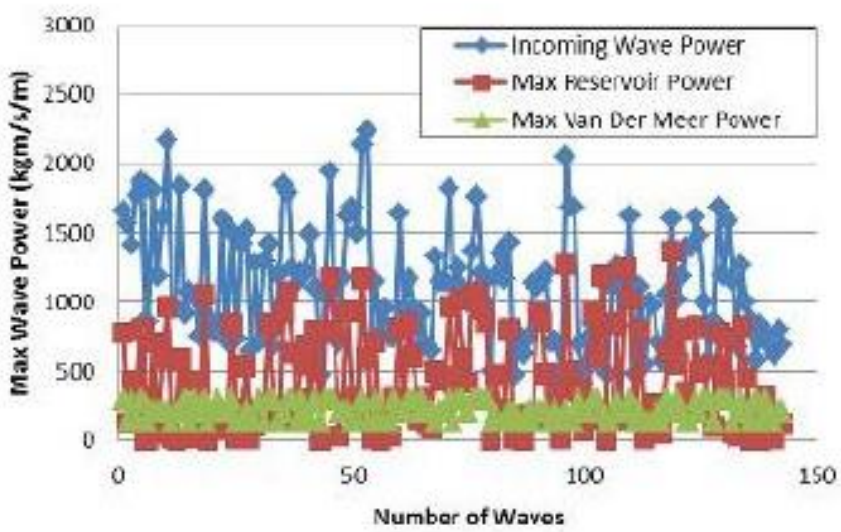

Fig. 4. The wave power availability and potentially mobilized [7]

The research result in Figure 4 shows that the waves are a huge potential energy source in the field. Not only because the wave power estimation that can be captured from the model is quite high, but the model has also a high economic and financial feasibility, because the model is made possible from the breakwater or coastal protection structure, so it can have multiple function as coastal defense and also wave energy converter. The development of this research will be widely open in the future, and proposed a huge potential to develop.

This paper focuses the discussion on overtopping devices, and the advantages of overtopping devices compared to the other type.

\section{Research method}

In order to meet the requirements of validity and high accuracy results, the research is done through physical modeling in the laboratory. The method used is an experimental simulation performed repeatedly with the condition of variable values that changed some variation to determine the effect of independent variables to the dependent variable (overtopping discharge-Q). The model with the slope of $30 \mathrm{o}$ tested by several variations of freeboard, water depth, wave height and period. Data acquisition using the WVFW (Wave View For Windows) application, by placing tools (probe 1) and (probe 2) to read the water fluctuation level of the model. Overtopping water volume, catching and measuring by reservoir model behind the slope model (see Figure 5 and Figure 6).

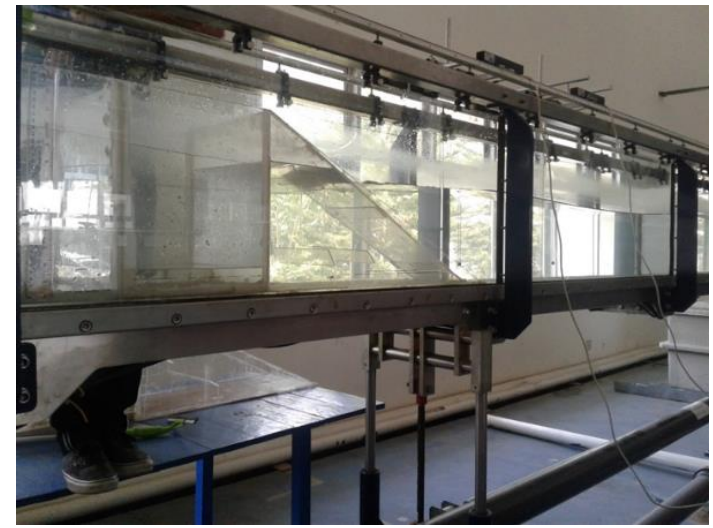

Fig. 5. Single slope model in the flume 


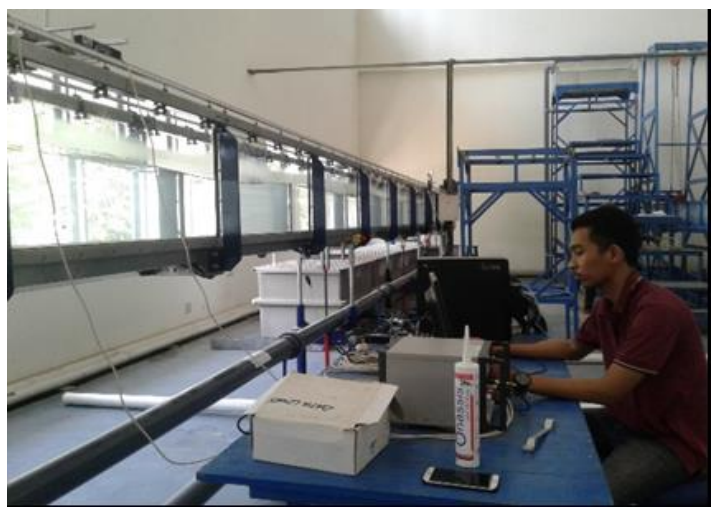

Fig. 6. Data acquisition tools.

Before the model run on, firstly has done tools calibration, especially wave height measuring instruments. The measuring scale on the computer system is correlated with the geometric size of the model. Two wave probes are placed in the upstream model to measure the maximum and minimum wave heights. The wave period is set by the variator contained in the wave generating machine. Total running done as much as 81 times on 3 kinds of struck (wave height adjustment) with each 3 kinds of high freeboard. The data acquisition from the probes is recorded in the computer system to describe the deformation of the waves that occur. The amount of overtopping volume is measured with a reservoir for 30 seconds each running section.

\section{Results and discussion}

\subsection{The Influence of Wave Characteristics}

To get an overview of the effect of wave parameters, especially wave height and wave period (Hi and T), the wave steepness parameter $(\mathrm{Hi} / \mathrm{L})$ is selected as the representative parameter. Therefore, it must first be calculated the wavelength (L) which is a function of the wave period (T) and the water depth (d). Figure 7 presents the relationship between wave steepness $(\mathrm{Hi} / \mathrm{L})$ with the Relative Overtopping Discharge $(\mathrm{Q} / \mathrm{Qo})$, where Qo is the total discharge by $\mathrm{Fb}=0$.

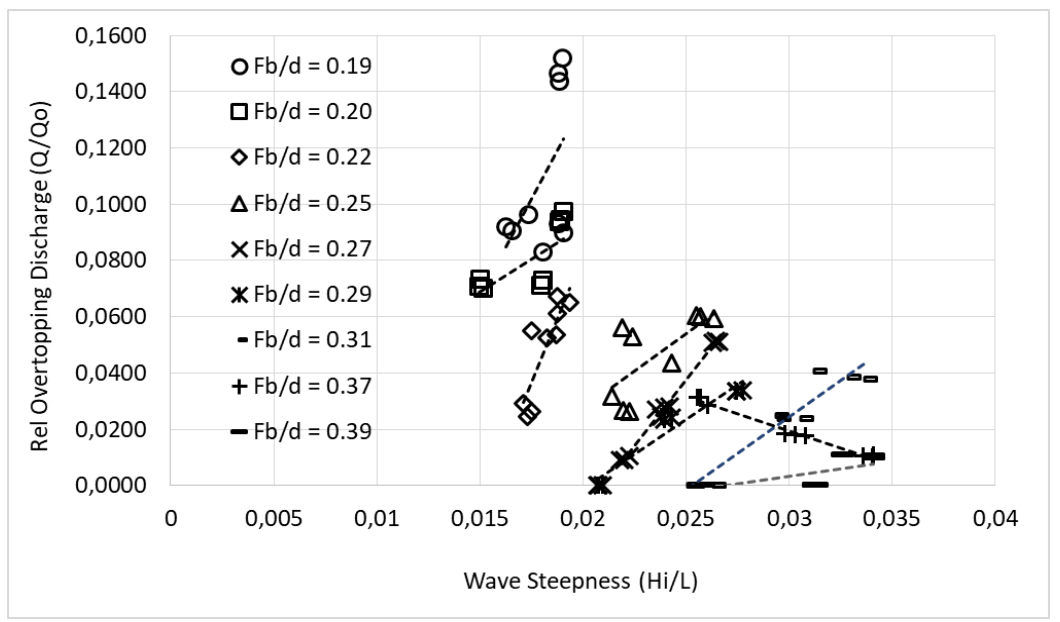

Fig. 7. Relationship between Wave Steepness $(H i / L)$ and the Rel. Overtopping Discharge $(Q / Q o)$ in the various of Freeboard height $(F b)$. 
From Figure 7 that can be describe that the increasing the wave steepness, the increasing the overtopping discharge in almost all trial freeboard height. Also, the increasing the freeboard height, the decreasing the overtopping discharge. Figure 8 presents the effect of wave reflection to the overtopping discharge.

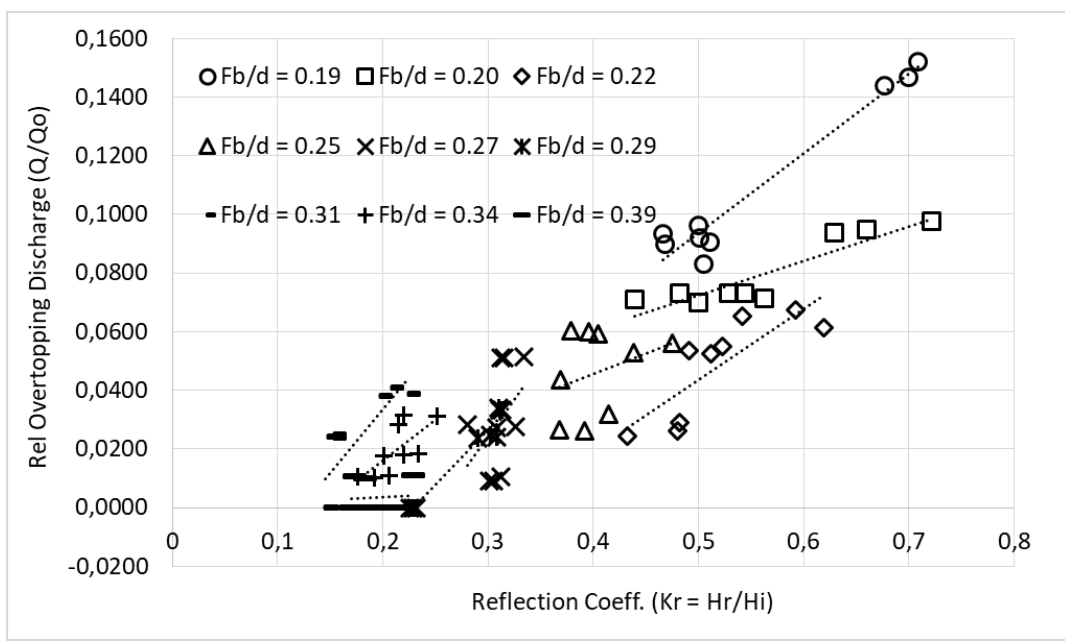

Fig. 8. Relationship between Reflection Coefficient (Kr) and Rel. Overtopping Discharge (Q/Qo) in the several of Freeboard height $(\mathrm{Fb})$.

Figure 8 shows, surprisingly, that the increasing the wave reflection is significantly contributing to the increasing of the overtopping discharge. This can be understood that the wave reflection has produced the standing waves that can fold twice as high as incoming waves. This happens with the superposition of the reflection wave with the incoming wave. More, The Figure 9 shows the standing wave number relationships with overtopping discharge.

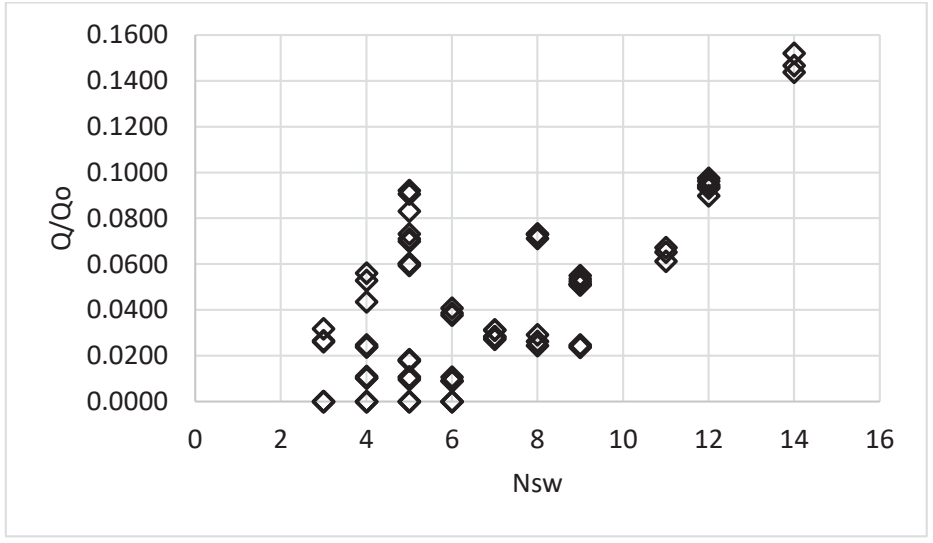

Fig. 9. The relationship between Numbers of Standing Waves (Nsw) and Rel. Overtopping Discharge (Q/Qo).

Figure 9 shows a fact that the increasing number of standing waves takes place, the increasing overtopping discharge that caught in the reservoir. This is a favorable condition in order for improving the wave energy capture performance for power plants.

\subsection{The Influence of Irribaren number}

The parameters of the coastal protection structures studied are the height of freeboard $(F b)$ and the slope structure relative to the wave steepness as generally mention as an Irribaren Number $\left(\operatorname{Ir}=\operatorname{Tan} \square /\left(H_{i} / L\right)^{0,5}\right)$. Figure 10 shows the effect of of the Irribaren Number as a dimensionless parameter to the relative overtopping discharge. 


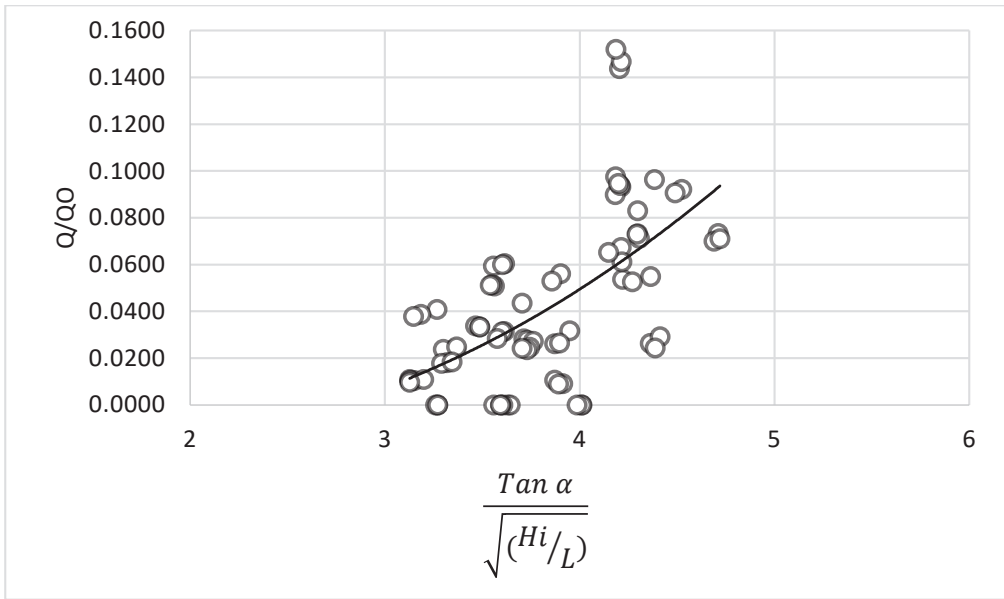

Fig. 10. Relationship between Irribaren Number (Ir) and Rel. Overtopping Discharge (Q/Qo).

Generally, Figure 10 shows that the increasing of $I r$, the increasing of $Q / Q o$ in the observed range.

\subsection{The influence of complete non-dimensional parameter (NDP).}

To obtain the combined effect of all independent variables on the overtopping discharge $(Q / Q o)$, it is necessary to develop a complete dimensionless parameter as a combination of all independent parameters through dimensional analysis. A simple dimensionless parameter is selected $F_{b} H_{i} / d L$ to illustrate its effect on $Q / Q o$ and the result is presented in Figure 11.

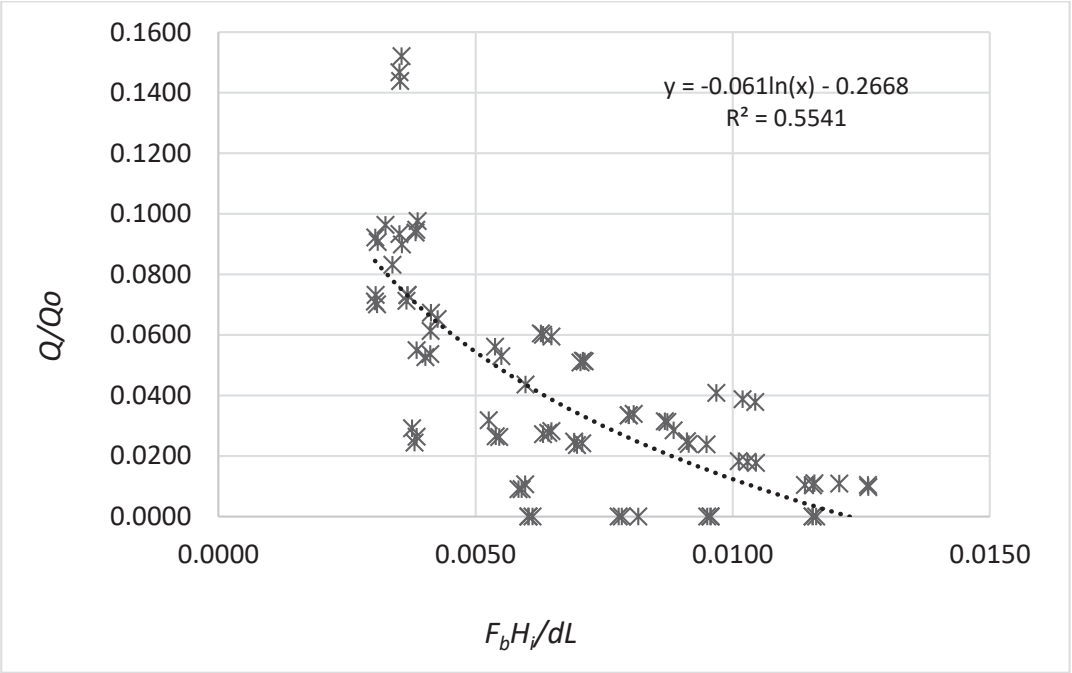

Fig. 11. Relationship between Completed NDP (FbHi/dL) and Rel. Overtopping Discharge (Q/Qo).

Based on the relationship of the NDP with $Q / Q o$, the empirical equation is obtained to calculate the amount of overtopping discharge that enters the reservoir:

$$
\frac{Q}{Q o}=-0.061 \ln F b \cdot \frac{H i}{d L}-0.2668
$$


From the above finding equation, the overtopping discharge $(Q)$ can be determined and the head $(h)$ such described in Figure 1 founded from experiment than the wave power in the reservoir can be determined in the consideration of the efficiency of the turbine.

\section{Conclusion}

The results showed that the overtopping discharge $(Q / Q o)$ much influenced by the height of freeboard relative to incoming wave height $\left(F_{b} / H_{i}\right)$, wave steepness $\left(H_{i} / L\right)$ in the Irribaren Number, reflection coefficient $(K r)$ and number of occurred standing waves $\left(N_{s w}\right)$. The increasing of $F_{b} / H_{i}$, the decreasing of $Q / Q o$, while the increasing of Irribaren Number (Ir) and reflection coefficient $(\mathrm{Kr})$, the increasing rate of $Q / Q o$. Standing waves in front of the structure due to the incident wave superposition with reflection waves also contribute to enlarge the overtopping discharge. It is found the empirical equation that can be used to determine the rate of overtopping discharge.

\section{References}

1. G.Bevilacqua, , \& B.Zanuttigh, Overtopping Wave Energy Converters: general aspects and stage of development. (2010)

2. S. F. Brito, Study of Overtopping at Coastal Structures, (2010).

3. M.Buccino, D.Stagonas, and D. Vicinanza. Development of a Composite Sea Wall Wave Energy Conversion System, Renewable Energy, 509-522, (2015)

4. B.Drew, A.Plummer, and M Sahinkaya, A Review of Wave Energy Converter Technology. IMechE, (887-902), Washington (2009).

5. B.Lee, and C. Lee, Development of Wave Power Generation Device with Resonance Channels. International Conference on Asian and Pacific Coasts (APAC), 533-537. Bali, (2013).

6. W. Sheng, R. Alcorn, and T. Lewis, Physical Modelling of Wave Energy Converters. Ocean Engineering, 29-36, (2014)

7. A. Thaha, F. Maricar, A.Aboe, and A.Dwipuspita, The Breakwater, from Wave Breaker to Wave Catcher. Procedia Engineering Elsevier, 691-698, (2015)

8. D.Vicinanza, P. Contestabile, J. Q. Nørgaard, and T. L.Andersen, Innovative rubble mound breakwaters for overtopping wave energy conversion. Coastal Engineering Elsevier, 154-170 (2014). 